\title{
Effects of postpartum uterine diseases on milk production and culling in dairy cows
}

\author{
J. Dubuc, ${ }^{\star 1,2}$ T. F. Duffield, ${ }^{\star}$ K. E. Leslie, ${ }^{\star}$ J. S. Walton, $†$ and S. J. LeBlanc ${ }^{\star}$ \\ *Department of Population Medicine, and \\ †Department of Animal and Poultry Science, University of Guelph, Guelph, Ontario, N1G 2W1, Canada
}

\begin{abstract}
The objective was to quantify the effect of postpartum uterine diseases on milk production and culling. Data from 2,178 Holstein cows in 6 herds enrolled in a randomized clinical trial were used. Milk production data from the first 4 Dairy Herd Improvement Association (DHIA) test-days and culling data from farm records were collected. Retained placenta $(\mathrm{RP} ; \geq 24 \mathrm{~h}$ after parturition) and metritis $[\leq 20 \mathrm{~d}$ in milk (DIM)] were diagnosed by farm managers using standardized definitions. Farms were visited weekly and cows were examined at 35 and $56( \pm 3)$ DIM using endometrial cytology (cytobrush device), vaginal discharge scoring (Metricheck device), and measurement of cervical diameter by transrectal palpation. Diagnostic criteria for cytological endometritis (CYTO) and purulent vaginal discharge (PVD) were established based on a detrimental effect on subsequent reproduction. Statistical analyses were performed using linear mixed models, logistic regression models, and Cox proportional hazard models, accounting for the effects of experimental treatments and herd clustering. Milk production and culling were the outcomes. Primiparous and multiparous cows were modeled separately for milk production. Milk production of primiparous cows was unaffected by uterine diseases. The effect of metritis on milk production was variable over time in multiparous cows: it decreased production per cow by $3.7 \mathrm{~kg}$ at the first DHIA test, but was not different at later tests. Retained placenta decreased milk production by $2.6 \mathrm{~kg} / \mathrm{d}$ in multiparous cows through the first 4 DHIA tests. The projected effects of metritis and RP in multiparous cows were reductions of $259 \mathrm{~kg}$ and $753 \mathrm{~kg}$ over 305 DIM, respectively; these effects were additive. Neither CYTO nor PVD affected milk production. Culling risks at 30 and 63 DIM were unaffected by RP and metritis. Culling hazard up to 300 DIM was unaffected by RP, metritis,
\end{abstract}

Received August 25, 2010.

Accepted December 2, 2010.

${ }^{1}$ Corresponding author: jocelyn.dubuc@umontreal.ca

${ }^{2}$ Current address: Faculté de médecine vétérinaire, Université de Montréal, C.P. 5000, Saint-Hyacinthe, Québec, J2S 7C6, Canada.
CYTO, or PVD, whether or not pregnancy status, milk production, and displaced abomasum were accounted for. Uterine disease decreased pregnancy rate, which was a substantial risk factor for culling; however, if affected cows became pregnant they were not at greater risk of culling.

Key words: uterine disease, dairy cow, milk production, culling

\section{INTRODUCTION}

Postpartum uterine diseases are common in dairy cows (Kelton et al., 1998; Sheldon et al., 2006; Overton and Fetrow, 2008). Metritis causes systemic signs of illness (fever, anorexia, decreased milk production) characterized by a foul-smelling, brown-red, watery vaginal discharge occurring within the first 20 DIM (Sheldon et al., 2006). Endometritis is diagnosed $>21$ DIM (Sheldon et al., 2006) and is classified based on its diagnostic technique (Dubuc et al., 2010). Cytological endometritis (CYTO) is an increased proportion of polymorphonuclear cells in endometrial cytology (Gilbert et al., 2005; Barlund et al., 2008). Clinical endometritis is defined as the presence of mucopurulent or purulent vaginal discharge after 21 DIM (LeBlanc et al., 2002). It was recently proposed that the term purulent vaginal discharge (PVD) be used instead of clinical endometritis, because PVD was not necessarily indicative of endometrial inflammation (Dubuc et al., 2010).

The effect of uterine diseases on reproduction is well established (Fourichon et al., 2000; LeBlanc et al., 2002; Gilbert et al., 2005), but studies investigating their effect on milk production have reported conflicting results (Bartlett et al., 1986; Rajala and Grohn, 1998; Fourichon et al., 1999). Differences in results may originate from major variations in the disease definitions used, which makes the comparison of studies difficult, and from the frequency of measurement of milk production (Fourichon et al., 1999). Nonetheless, metritis decreased daily milk production from 2 to $13 \mathrm{~kg}$ during a period that can vary from 2 to $20 \mathrm{wk}$ after parturition (Rajala and Grohn, 1998; Fourichon et al., 1999; Wittrock et 
al., 2009). The effect of metritis on milk production was reported to be influenced by parity and stage of lactation (Overton and Fetrow, 2008; Wittrock et al., 2009). The presence of PVD was not associated with an effect on milk production (Fourichon et al., 1999).

The reported effect of uterine diseases on culling is variable. Some studies found an increased risk of culling (Oltenacu et al., 1990; Overton and Fetrow, 2008), whereas others found no effect (Bartlett et al., 1986; Gröhn et al., 1998). Disease definition, duration of the follow-up period, sample size (power), and accounting for related diseases are important factors contributing to this discrepancy. In studies in which uterine diseases increased culling, this was suggested to be the result of either decreased milk production or reduced reproductive performance (Gröhn and Rajala-Schultz, 2000; Overton and Fetrow, 2008).

The objectives were to quantify the effect of postpartum uterine diseases on milk production and culling. The hypotheses were that metritis would have a negative effect on milk production and lead to increased culling in the early postpartum period, whereas CYTO and PVD would only increase culling later in lactation.

\section{MATERIALS AND METHODS}

\section{Data Collection}

Data from 2,178 cows enrolled in a randomized clinical trial investigating the effect of antibiotic and $\mathrm{PGF}_{2 \alpha}$ treatments on uterine health and reproduction (Dubuc et al., 2011) were analyzed to measure the association between postpartum uterine diseases and milk production and culling. The study was conducted from September 2007 to November 2008. Cows calved during this time period. Briefly, cows were from 6 commercial Holstein herds housed in freestall barns with 300 to 1,000 milking cows, including 3 herds in southwestern Ontario (Canada) and 3 herds in western New York State. Participating herds were recruited based on convenience, but were required to use monthly DHIA milk recording service.

Farms were visited weekly by a research technician and a veterinarian. Cows were examined at 35 and $56( \pm 3)$ DIM. Examination procedures included the collection of endometrial cytology samples using the cytobrush technique (Kasimanickam et al., 2004), the inspection of vaginal discharge using the Metricheck device (Simcro, Waikato, New Zealand) and score (McDougall et al., 2007), and the measurement of cervical diameter by transrectal palpation. Diagnostic criteria for CYTO and PVD were established based on detrimental effect on subsequent reproductive performance, as reported elsewhere (Dubuc et al., 2010). In summary,
CYTO was defined as the presence of $\geq 6$ and $\geq 4 \%$ polymorphonuclear cells in endometrial cytology at 35 and 56 DIM, respectively. Purulent vaginal discharge was defined as the presence of mucopurulent or purulent vaginal discharge at either examination. Cervical diameter was not identified as a diagnostic criterion for CYTO or PVD. Cows were classified at each examination according to their uterine health status as having CYTO only, PVD only, both CYTO and PVD (both), or being unaffected.

Individual cow data were recorded on farm by using the DairyComp 305 software (Valley Agricultural Software, Tulare, CA). Metritis, retained placenta (RP), displaced abomasum, and culling data were recorded by farm managers, and their definitions were standardized at the start of the study. Metritis was defined as foul-smelling, brown-red, watery vaginal discharge with rectal temperature $>39.5^{\circ} \mathrm{C}$ before 20 DIM (Sheldon et al., 2006). Retained placenta was defined as the retention of fetal membranes $\geq 24 \mathrm{~h}$ after parturition. Cows were followed for culling until 300 DIM. Milk production data were collected from the monthly DHIA milk recording program. Data included milk weight, fat and protein percentages, SCC, and 305-d projection of milk production for each of the first 4 DHIA test-days after calving. Individual cow parity group (first; second or greater) and season of calving (winter: December to February; spring: March to May; summer: June to August; fall: September to November) were also recorded.

\section{Statistical Analyses}

Individual cow data were exported from DairyComp 305 to Microsoft Excel (Microsoft Corp., Redmond, WA). Statistical analyses were performed with SAS (version 9.2, SAS Institute Inc., Cary, NC), considering the cow as the unit of interest. Milk production and culling data were the outcomes.

Statistical analyses of milk production were performed in 3 steps. First, a linear mixed model (MIXED procedure) considering herd as a random effect was built for each test-day milk production outcome. Experimental treatment effects, parity group, DIM at test-day, and its quadratic term when appropriate, were forced into the models. Each model was offered the predictors season, RP, twins, dystocia, metritis, uterine health status (CYTO only, PVD only, both), and biologically meaningful interactions with the significant main effects. A manual backward elimination procedure was used to build the final model until only significant $(P$ $<0.05)$ predictors were retained. Residual distribution was assessed for homoscedasticity and normality, and least squares means were obtained for significant predictors. If an interaction term between parity and a 
Table 1. Dairy Herd Improvement test-day milk production data from Holstein cows in 6 commercial herds enrolled in a study investigating the effects of uterine diseases on milk production and culling

\begin{tabular}{|c|c|c|c|}
\hline Sampling time & $\mathrm{n}$ & Mean & SD \\
\hline \multicolumn{4}{|l|}{ Test-day 1} \\
\hline DIM & 2,050 & 20.2 & 10.3 \\
\hline Milk production $(\mathrm{kg} / \mathrm{d})$ & 2,050 & 37.6 & 12.7 \\
\hline Milk production projection $(\mathrm{kg} / 305 \mathrm{~d})$ & 2,050 & 10,210 & 2,177 \\
\hline Fat $(\%)$ & 1,968 & 4.16 & 0.99 \\
\hline Protein $(\%)$ & 1,968 & 3.07 & 0.42 \\
\hline $\mathrm{LSCC}^{1}$ & 1,968 & 2.4 & 0.3 \\
\hline \multicolumn{4}{|l|}{ Test-day 2} \\
\hline DIM & 1,978 & 53.4 & 11.2 \\
\hline Milk production (kg/d) & 1,978 & 43.9 & 12.1 \\
\hline Milk production projection $(\mathrm{kg} / 305 \mathrm{~d})$ & 1,978 & 11,298 & 2,427 \\
\hline Fat $(\%)$ & 1,967 & 3.52 & 0.71 \\
\hline Protein (\%) & 1,967 & 2.83 & 0.25 \\
\hline LSCC & 1,967 & 2.2 & 0.3 \\
\hline \multicolumn{4}{|l|}{ Test-day 3} \\
\hline DIM & 1,930 & 86.5 & 13.4 \\
\hline Milk production $(\mathrm{kg} / \mathrm{d})$ & 1,930 & 42.3 & 11.2 \\
\hline Milk production projection $(\mathrm{kg} / 305 \mathrm{~d})$ & 1,930 & 11,671 & 2,436 \\
\hline Fat $(\%)$ & 1,920 & 3.44 & 0.69 \\
\hline Protein (\%) & 1,920 & 2.93 & 0.67 \\
\hline LSCC & 1,920 & 2.1 & 0.3 \\
\hline \multicolumn{4}{|l|}{ Test-day 4} \\
\hline DIM & 1,890 & 119.1 & 16.1 \\
\hline Milk production (kg/d) & 1,890 & 42.3 & 10.7 \\
\hline Milk production projection $(\mathrm{kg} / 305 \mathrm{~d})$ & 1,890 & 12,024 & 2,604 \\
\hline Fat $(\%)$ & 1,881 & 3.46 & 0.68 \\
\hline Protein (\%) & 1,881 & 3.02 & 0.27 \\
\hline LSCC & 1,881 & 2.0 & 0.3 \\
\hline
\end{tabular}

${ }^{1}$ Linear score of SCC.

uterine disease was significant, stratified models were built for primiparous and multiparous cows. Second, a linear mixed model (MIXED procedure) was built considering herd as a random effect and repeated measures of test-day milk production within cow. Different correlation structures for repeated measures were assessed, and the one providing the lowest model Akaike's information criterion was selected. Model building and assessment were performed using the same predictors and procedures as above. Third, 305-d milk projection from the third test-day was used as the outcome in a linear mixed model (MIXED procedure), considering herd as a random effect, to assess the effect of uterine diseases on milk production during the entire lactation. Model building and assessment were performed using the same predictors and procedures as described for the first step.

Three statistical analyses for culling were performed. First, variables representing the culling status of each cow at 30,63, and 300 DIM were created. Univariable logistic regression models (GLIMMIX procedure) considering herd as a random effect were used to determine the effect of uterine diseases on all culling outcomes. Second, multivariable logistic mixed models (GLIMMIX procedure) considering herd as a random effect were used to assess the effect of uterine diseases on the probability of culling during the early postpartum period (30 and 63 DIM). Experimental treatment effects were forced into the models. Predictors offered to the models were parity group, season, RP, twins, dystocia, metritis, uterine health status (CYTO only, PVD only,

Table 2. Incidence of uterine diseases and culling in Holstein cows in 6 commercial herds enrolled in a study investigating the effect of uterine diseases on milk production and culling

\begin{tabular}{|c|c|c|}
\hline Event & $\mathrm{n}$ & $\begin{array}{c}\text { Incidence } \\
(\%)\end{array}$ \\
\hline Metritis ${ }^{1}$ & 2,178 & 19.7 \\
\hline Uterine diseases $^{2}$ at $35( \pm 3)$ DIM & & \\
\hline CYTO only & 2,072 & 13.2 \\
\hline PVD only & 2,072 & 9.4 \\
\hline Both & 2,072 & 6.7 \\
\hline Uterine diseases at $56( \pm 3)$ DIM & & \\
\hline CYTO only & 2,022 & 9.8 \\
\hline PVD only & 2,022 & 7.2 \\
\hline Both & 2,022 & 4.0 \\
\hline Culling & & \\
\hline$\leq 30$ DIM & 2,178 & 3.7 \\
\hline$\leq 63 \mathrm{DIM}$ & 2,178 & 6.9 \\
\hline$\leq 300$ DIM & 2,178 & 17.5 \\
\hline
\end{tabular}

${ }^{1}$ Foul-smelling uterine discharge and fever $\leq 20$ DIM.

${ }^{2} \mathrm{CYTO}=$ cytological endometritis $(>6 \%$ polymorphonuclear cells at endometrial cytology); PVD = purulent vaginal discharge (mucopurulent or purulent vaginal discharge); Both = CYTO and PVD. 
A)

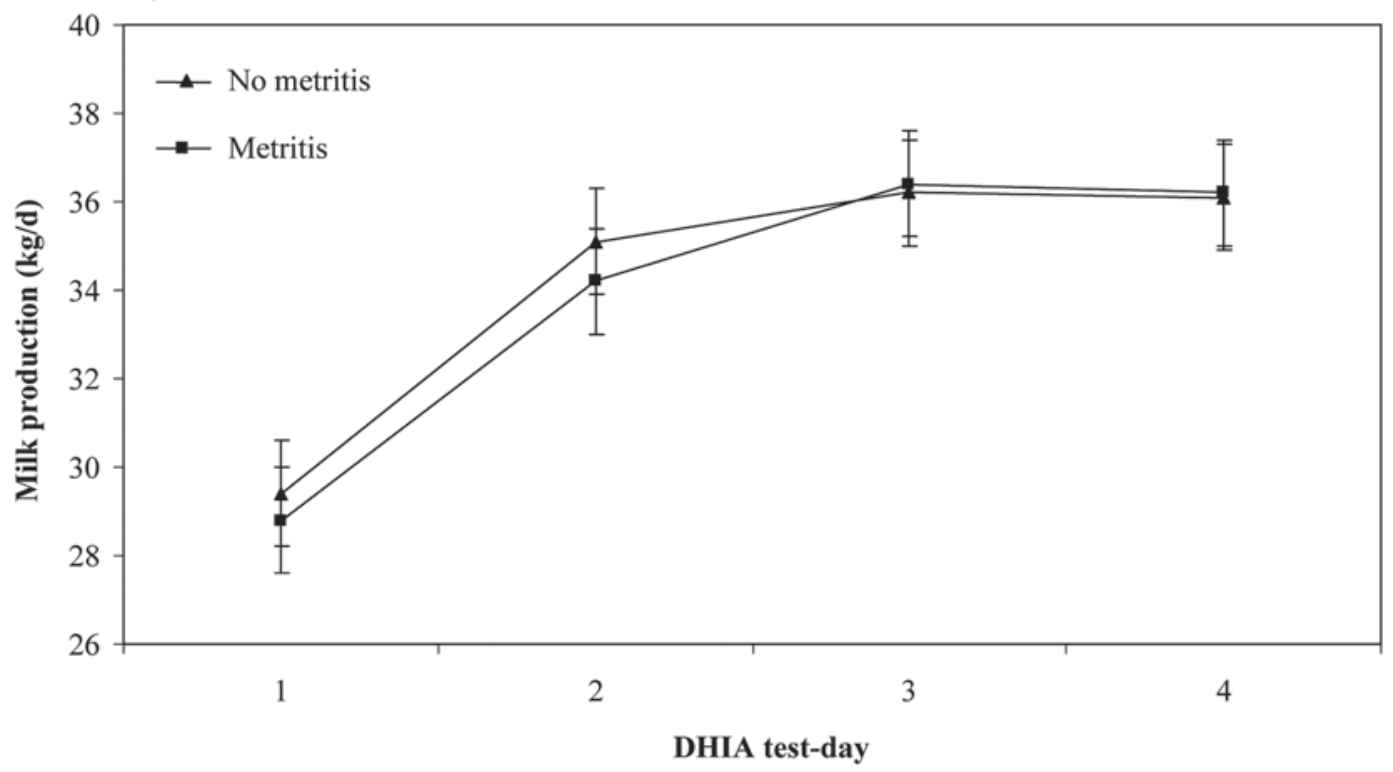

B)

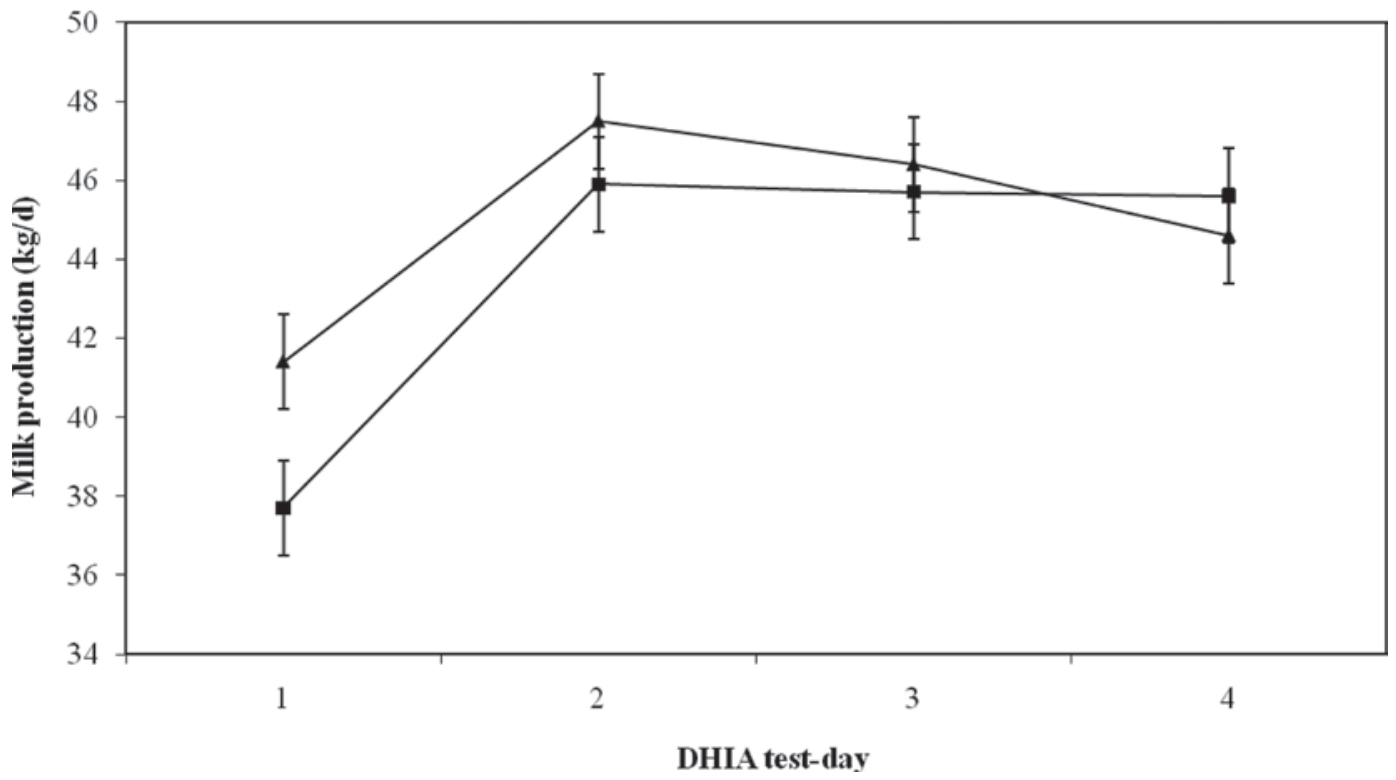

Figure 1. Effect of metritis on milk production in (A) primiparous cows and (B) multiparous cows at the first 4 DHIA test-days, accounting for the fixed effects of treatment, parity, and retained placenta (RP), and the random effect of herd, in 2,050 Holstein cows.

both), milk production at first test-day, DIM at first test-day, and interactions with significant main effects. A manual backward elimination procedure was used to build the final model of both outcomes until all predictors were significant $(P<0.05)$. A very similar model that did not consider milk production as a predictor was built to assess whether milk production could be an intervening variable between metritis and culling. Third, a Cox proportional hazard model (PHREG procedure) was used to assess time to culling in a survival analysis, where herds were treated as strata to adjust for herd clustering (Gröhn et al., 1998). Experimental treatment effects were forced into the model. Predictors offered to the model and model building procedures were the same as for the logistic regression model above. The assumption of the proportionality of hazards in the model was assessed graphically by plotting the logarithm of the hazard function by the logarithm of the time. If a predictor did not have proportional hazards over time, an interaction term of the $\log$ time at risk and the predictor was forced into the model (Dohoo et al., 2003). 
A)

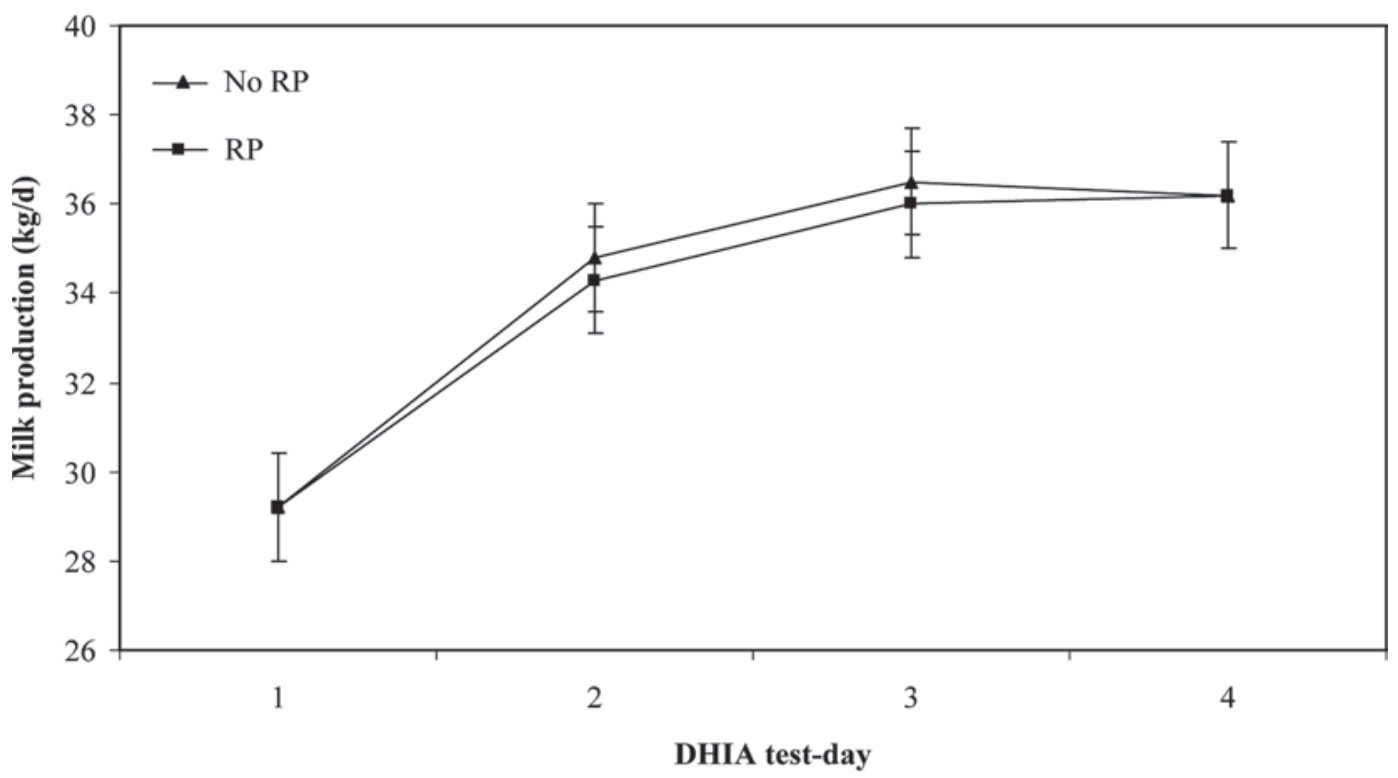

B)

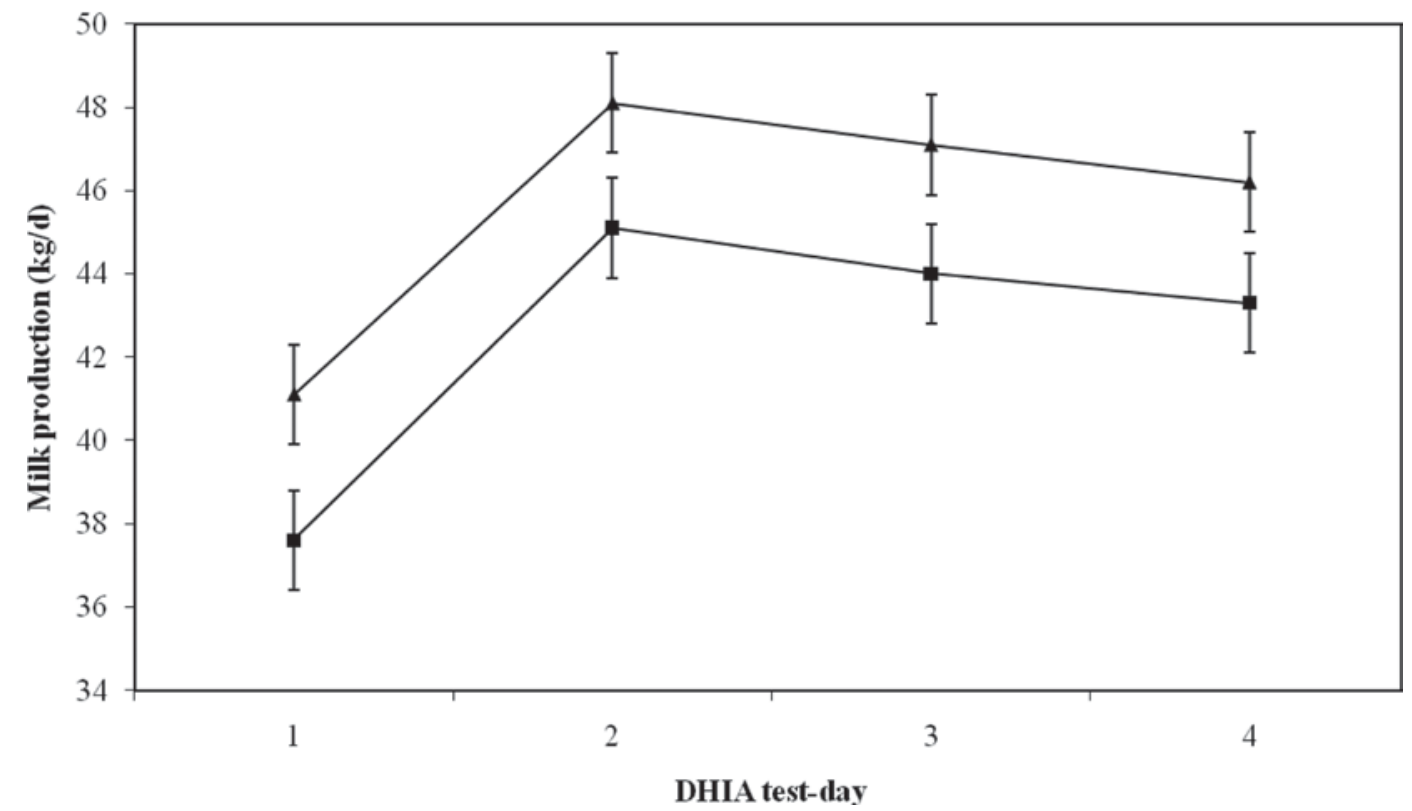

Figure 2. Effect of retained placenta (RP) on milk production in A) primiparous and B) multiparous cows at the first 4 DHIA test-days, accounting for the fixed effects of treatment, parity, and metritis, and the random effect of herd, in 2,050 Holstein cows.

\section{RESULTS}

Data from 2,178 cows were obtained for this study. Descriptive statistics for milk production are given in Table 1, and the incidence of uterine diseases and culling are shown in Table 2. The experimental treatments from the clinical trial had no effects on milk production or culling, but these variables were forced in all models.
The effect of metritis on milk production depended on parity group $(P<0.01$; Figure $1 \mathrm{~A}, \mathrm{~B})$. The effect of metritis on milk production was variable over time in multiparous cows: it decreased milk production by $3.7 \mathrm{~kg} /$ cow at first test-day $(P=0.03$; Figure 1B) but was not different at the subsequent 3 tests $(P>0.20)$. Retained placenta was a confounding variable because its removal from the model caused a change of $>25 \%$ of 
Table 3. Univariable effect of retained placenta (RP) and metritis, accounting for the clustering effect of herd $(\mathrm{n}=6)$, on culling and pregnancy risks in 2,178 Holstein cows

\begin{tabular}{|c|c|c|c|c|c|c|}
\hline \multirow[b]{2}{*}{ Item } & \multicolumn{2}{|c|}{$\mathrm{RP}$} & \multirow[b]{2}{*}{$P$-value } & \multicolumn{2}{|c|}{ Metritis } & \multirow[b]{2}{*}{$P$-value } \\
\hline & No & Yes & & No & Yes & \\
\hline \multicolumn{7}{|c|}{ Culling risk (\%) } \\
\hline 30 DIM & 3.2 & 6.3 & 0.34 & 3.6 & 4.5 & 0.70 \\
\hline 63 DIM & 6.4 & 9.0 & 0.71 & 6.8 & 7.2 & 0.92 \\
\hline 300 DIM & 16.9 & 18.5 & 0.69 & 17.0 & 18.0 & 0.83 \\
\hline \multicolumn{7}{|c|}{ Pregnancy risk (\%) } \\
\hline First service & 34.7 & 29.4 & 0.02 & 35.3 & 27.2 & $<0.01$ \\
\hline 120 DIM & 46.5 & 33.2 & $<0.01$ & 46.0 & 36.3 & $<0.01$ \\
\hline 300 DIM & 83.5 & 76.0 & $<0.01$ & 82.6 & 80.4 & 0.02 \\
\hline
\end{tabular}

the coefficient for metritis (Dohoo et al., 2003). Therefore, $\mathrm{RP}$ was retained in the final model with metritis. The reduction of $2.6 \mathrm{~kg} / \mathrm{cow}$ in test-day milk production in multiparous cows with RP was present across the first 4 test-days $(P<0.05$; Figure 2B). Based on projected $305-\mathrm{d}$ production at the third test-day, multiparous cows with RP or metritis produced $753 \mathrm{~kg}(P$ $<0.01)$ and $259 \mathrm{~kg}(P<0.01)$ less milk per lactation, respectively, than unaffected cows; these effects were additive. Test-day milk production of primiparous cows was unaffected by metritis $(P=0.46$; Figure $1 \mathrm{~A})$ or RP $(P=0.35$; Figure $2 \mathrm{~A})$. Therefore, $305-\mathrm{d}$ projected production in primiparous cows was unaffected by metritis $(P=0.72)$ or $\mathrm{RP}(P=0.57)$. Cytological endometritis and PVD had no effect on test-day $(P>0.20)$ or $305-\mathrm{d}$ projected $(P>0.73)$ milk production in either primiparous or multiparous cows.

The univariable effects of RP and metritis on culling and pregnancy risks are shown in Table 3 . The effect of uterine diseases on culling risk at 30 and 63 DIM was determined in multivariable logistic regression models, including milk production at first test-day as one of the predictors or not (i.e., to assess whether early lactation production was an intervening variable between uterine disease and culling in early lactation). With both approaches, metritis, RP, CYTO, and PVD were not associated with culling by 63 DIM $(P>0.20)$. The effect of uterine diseases on full-lactation culling was assessed in a Cox proportional hazard model (Table 4 ), including pregnancy status and milk production as covariates or not (i.e., to assess whether pregnancy or level of production were intervening variables between uterine disease and culling). Metritis, RP, CYTO, and PVD were not associated with the hazard of culling for 300 DIM $(P>0.20)$, whether or not accounting for pregnancy status and milk production. Nonpregnant cows were at greatly increased risk, and multiparous and low-producing cows were at increased hazard of being culled by 300 DIM.

\section{DISCUSSION}

Metritis had a detrimental effect on milk production in multiparous cows, but not in primiparous cows. This supports another study (Wittrock et al., 2009) in which the effect of metritis on production in multiparous animals lasted for $200 \mathrm{~d}$ after calving, whereas it was only seen at first test-day in the current study. Using daily milk data from 88 cows in 1 herd, Wittrock et al. (2009) reported a decrease in milk production of 2,647 $\mathrm{kg}$ for the entire lactation (305 d) of multiparous cows, which was greater than that in the present study (decrease of $259 \mathrm{~kg}$ ). Another study using daily milk data from 500 cows in 1 herd reported a detrimental effect of metritis on milk production in all cows that was greater per day among cows culled <60 DIM, but lasted up to 110 DIM among cows that were not culled (Overton and Fetrow, 2008). Although these studies had a disease definition for metritis similar to that used in the present study, the differences in results could be explained by many factors. Previous studies (Overton and Fetrow, 2008; Wittrock et al., 2009) used data from only 1 herd, whereas the present study involved sampling from multiple herds, which could imply a variation of effect between herds. On the other hand, previous studies used daily measurement of milk production, whereas the present study used monthly test-day measurements. The 305-d projection from the third DHIA test was used for estimation of full lactation production because this measure was more accurate than those based on the first or second test days (Quist et al., 2007). Although test-day measurement is reliable for full lactation measurements, it may not be the most sensitive method to detect the detrimental effect of metritis on milk production, which appears to be of short duration. It may not consider cows culled early (before third testday) and potentially affected by metritis.

The present study was one of the first to account simultaneously for the effect of RP and metritis on milk 
Table 4. Final Cox proportional hazard model of time to culling up to 300 DIM, accounting for the clustering effect of herd $(\mathrm{n}=6)$, in 2,178 Holstein cows

\begin{tabular}{llccccc}
\hline & & & & Hazard & $95 \%$ & \\
Variable & Level & Coefficient & SE & ratio & CI & $P$-value \\
\hline Pregnancy & Yes & -2.85 & 0.17 & 0.06 & $0.04-0.08$ & $<0.01$ \\
Parity & $\geq 2$ & 0.99 & 0.20 & 2.69 & $1.82-3.99$ & $<0.01$ \\
Displaced abomasum $^{1}$ & Yes & 0.96 & 0.30 & 2.62 & $1.47-4.68$ & $<0.01$ \\
Milk production $^{2}$ (per $\left.1,000 \mathrm{~kg} / 305 \mathrm{~d}\right)$ & & -0.18 & 0.02 & 0.84 & $0.76-0.92$ & $<0.01$ \\
\hline
\end{tabular}

${ }^{1}$ Occurring during the current lactation.

${ }^{2}$ From projection at third DHIA test-day.

production. Studies by Overton and Fetrow (2008) and Wittrock et al. (2009) did not account for RP. Interestingly, the results from the present study suggest that the effects of metritis and RP are different and additive when both are experienced by multiparous cows. From the present results, multiparous cows with RP experienced a decrease in milk production of $759 \mathrm{~kg}$ per lactation. If the same cows develop metritis, they have a total decrease of $1,018 \mathrm{~kg}$ per lactation. It is unclear why RP alone would cause a decrease in milk production, if not inducing systemic signs of illness (i.e., progressing to metritis). It is possible, and merits specific future investigation, that the effect of RP is not only to substantially increase the risk of metritis and PVD. Perhaps multiparous cows with RP that do not progress to further reproductive tract disease consumed less feed or were affected otherwise so that milk production was reduced. Prepartum issues leading to decreased DMI and immunosuppression may be associated with a decrease in milk production in RP cows.

Cytological endometritis and PVD had no effect on milk production. This makes biological sense because both conditions are localized to the reproductive tract. This finding supports previous studies reporting that PVD did not influence milk production (Fourichon et al., 1999).

It was expected that metritis and $\mathrm{RP}$ would increase culling in early (30 DIM) or late lactation (300 DIM). However, RP, metritis, CYTO, and PVD had no effect on culling risk at 30 and 63 DIM or on the culling hazard to 300 DIM after accounting or not for milk production. Insufficient sample size may explain the lack of statistical difference for culling risk at 30 DIM (RP), but a large-scale study reported similar results for metritis when accounting for RP (Gröhn et al., 1998). In that study, RP was associated with an increased risk of culling in later lactation, whereas, in the present study, RP had no effect. It appears from the present results that milk production losses associated with metritis and RP may not be sufficient to increase the culling risk of the affected cows. It was surprising that the decrease in reproductive performance caused by CYTO and PVD
(Dubuc et al., 2010, 2011) did not increase culling in the present study. Although uterine disease was associated with reduced reproductive performance, it was not in itself a risk factor for culling; the level of milk production and eventual pregnancy of affected cows appeared to supersede the effect of uterine disease in early lactation with respect to culling decisions. Although the pregnancy status of cows had a very important effect on the hazard of culling, many factors other than uterine diseases also affect pregnancy status (LeBlanc, 2008). Following these cows for a longer period might have shown a different culling risk.

\section{CONCLUSIONS}

Metritis and RP decreased milk production in multiparous cows, but CYTO and PVD did not in any cows. Culling hazard up to 300 DIM was unaffected by uterine diseases. Reproductive diseases make pregnancy less likely, which was a substantial risk factor for culling, but if affected cows became pregnant or had sufficiently high milk production, they were not at greater risk of culling. Because the conditions are interrelated, large-scale field studies that consider all forms of reproductive disease are needed to evaluate their economic effect in dairy herds.

\section{ACKNOWLEDGMENTS}

This project was financially supported by Pfizer Animal Health (Kirkland, Québec, Canada). The authors thank the participating farmers, veterinarians, and technical staff for their involvement.

\section{REFERENCES}

Barlund, C. S., T. D. Carruthers, C. L. Waldner, and C. W. Palmer. 2008. A comparison of diagnostic techniques for postpartum endometritis in dairy cattle. Theriogenology 69:714-723.

Bartlett, P. C., J. H. Kirk, M. A. Wilke, J. B. Kaneene, and E. C. Mather. 1986. Metritis complex in Michigan Holstein-Friesian cattle: Incidence, descriptive epidemiology and estimated economic impact. Prev. Vet. Med. 4:235-248.

Dohoo, I., W. Martin, and H. Stryhn. 2003. Veterinary Epidemiologic Research. 1st ed. AVC Inc., Charlottetown, Prince Edward Island, Canada. 
Dubuc, J., T. F. Duffield, K. E. Leslie, J. S. Walton, and S. J. LeBlanc. 2010. Definitions and diagnosis of postpartum endometritis in dairy cows. J. Dairy Sci. 93:5225-5233. doi:10.3168/jds.20103428.

Dubuc, J., T. F. Duffield, K. E. Leslie, J. S. Walton, and S. J. LeBlanc. 2011. Randomized clinical trial of antibiotic and prostaglandin treatments for uterine health and reproductive performance in dairy cows. J. Dairy Sci. 94:1325-1338. doi:10.3168/jds.20103757.

Fourichon, C., H. Seegers, N. Bareille, and F. Beaudeau. 1999. Effects of disease on milk production in the dairy cow: A review. Prev. Vet. Med. 41:1-35.

Fourichon, C., H. Seegers, and X. Malher. 2000. Effect of disease on reproduction in the dairy cow: A meta-analysis. Theriogenology 53:1729-1759.

Gilbert, R. O., S. T. Shin, C. L. Guard, H. N. Erb, and M. Frajblat. 2005. Prevalence of endometritis and its effects on reproductive performance of dairy cows. Theriogenology 64:1879-1888.

Gröhn, Y. T., S. W. Eicker, V. Ducrocq, and J. A. Hertl. 1998. Effect of diseases on the culling of Holstein dairy cows in New York state. J. Dairy Sci. 81:966-978.

Gröhn, Y. T., and P. J. Rajala-Schultz. 2000. Epidemiology of reproductive performance in dairy cows. Anim. Reprod. Sci. 6061:605-614.

Kasimanickam, R., T. F. Duffield, R. A. Foster, C. J. Gartley, K. E. Leslie, J. S. Walton, and W. H. Johnson. 2004. Endometrial cytology and ultrasonography for the detection of subclinical endometritis in postpartum dairy cows. Theriogenology 62:9-23.

Kelton, D. F., K. D. Lissemore, and R. E. Martin. 1998. Recommendations for recording and calculating the incidence of selected clinical diseases of dairy cattle. J. Dairy Sci. 81:2502-2509.
LeBlanc, S. J. 2008. Case study - Effect of implementation of a systematic reproduction management program in dairy herds. Bovine Pract. $42: 181-188$.

LeBlanc, S. J., T. F. Duffield, K. E. Leslie, K. G. Bateman, G. P. Keefe, J. S. Walton, and W. H. Johnson. 2002. Defining and diagnosing postpartum clinical endometritis and its impact on reproductive performance in dairy cows. J. Dairy Sci. 85:2223-2236.

McDougall, S., R. Macaulay, and C. Compton. 2007. Association between endometritis diagnosis using a novel intravaginal device and reproductive performance in dairy cattle. Anim. Reprod. Sci. 99:9-23.

Oltenacu, P. A., A. Frick, and B. Lindhé. 1990. Epidemiological study of several clinical diseases, reproductive performance and culling in primiparous Swedish cattle. Prev. Vet. Med. 9:59-74.

Overton, M., and J. Fetrow. 2008. Economics of postpartum uterine health. Pages 39-43 in Proc. Dairy Cattle Reprod. Council Conv. Omaha, NE. Dairy Cattle Reproductive Council, Hartland, WI.

Quist, M. A., S. J. LeBlanc, K. J. Hand, D. Lazenby, F. Miglior, and D. F. Kelton. 2007. Agreement of predicted 305-day milk yields relative to actual 305-day milk weight yields. J. Dairy Sci. 90:4684-4692.

Rajala, P. J., and Y. T. Grohn. 1998. Effects of dystocia, RP, and metritis on milk yield in dairy cows. J. Dairy Sci. 81:3172-3181.

Sheldon, I. M., G. S. Lewis, S. LeBlanc, and R. O. Gilbert. 2006 Defining postpartum uterine disease in cattle. Theriogenology 65:1516-1530.

Wittrock, J. M., K. L. Proudfoot, D. M. Weary, and M. A. G. von Keyserlingk. 2009. Metritis causes long term decreases in the milk production of multiparous Holstein dairy cows. Page 190 in Proc. 44th Ann. Pacific Northwestern Anim. Nutr. Conf., Boise, ID. Pacific Northwestern Animal Nutrition Association, Portland, OR. 